\title{
On the Integration of National Costume Elements and Modern Costume Design
}

\author{
Sun Ning; Zhan Qinchuan \\ College of Art and Design, Shaanxi University of Science and Technology, Xi' 'an Shaanxi 710054
}

\begin{abstract}
With the increasing development of modern national costume design, the integration of national costume elements and modern costume design has been in widely application and has become the focus of modern costume designers. In order to protect and develop the essence of the traditional national culture, it is necessary to further explore and flexibly apply national costume elements, to find the joint point between national culture and modern elements, and to create modern costume which is rich in national characteristics. The paper describes the main content of national costume elements and the meaning of its application to modern costume design, discusses the specific content of the integration of national costume elements and modern costume design, and further reflects the profound traditional culture by using modern design language which makes the works vintage and modern.
\end{abstract}

Keywords: elements; national costume; modern costume design; development

\section{Introduction}

Traditional culture and art can provide abundant design materials and creative concepts for modern costume design. Ethnic national costume stresses bright colors, exquisite technology and unique style. While national costume has different styles because of regional and custom differences in different nationalities. National costume seems to be plain, mysterious and magnificent, but it implies deep philosophy and is the main source of modern art design. Excellent traditional national costume is the essence of national culture as well as the important material of modern costume design. The feeling embodied in national culture is what modern people yearn and pursue in the aspect of costume. Therefore, in order to design innovative costume, modern designers have to work hard to dig and take in excellent national costume elements, closely integrate it with modern costume design, which is the best way to protect and inherit national costume culture.

\section{Implication of National Costume Elements and Meaning of its Application to Costume Design}

National costume elements are the main element of national costume, such as styling, shell fabric, pattern, craft, which are divided into visual elements and spiritual elements. Visual elements refer to visually pictorial and specific elements, like cheongsam, embroidered skirt and the pleated skirt of the Miao nationality from which we can obviously feel the styling with national characteristics. However, spiritual elements refer to the intangible spirit contained in national costume, which mainly includes the unique spiritual tradition, such as the well-disciplined and middle-ground attitude advocated by the Confusion school, the distinctive styling and national color included in traditional national costume, and national aesthetic psychology included in the costume pattern. Therefore, applying national costume elements to modern costume design plays an important role.

\subsection{Protect National Costume during Com- munications and the Development}

Modern costume design mainly emphasizes economization, practicability and industrialization, which is unconsciously changing the aesthetics of modern people. Now, exquisite costume made by hand is replaced by a large number of industrial products. Although the emerging decorative material can increase the efficiency of costume production and take on a new look, it also makes national costume products made like this be short of the plain and natural feature which is supposed to have. Currently, national costume is influencing modern fashion costume. Applying national costume elements to modern fashion costume is beneficial to re-recognize national cultural tradition and to inherit and develop national costume culture.

\subsection{Inherit Tradition and Create Costume Style}

With the increasing development of tourism and the constant increase of cultural communications with foreign countries, colorful costume of all nationalities gradually attracts people's attention, especially the characteristics of numerous variety, peculiar style, bright color and exquisite pattern. Many domestic and overseas costume designers use the essence of our national culture, and integrate national costume elements with 
modern costume design to make modern costume having more characteristics. Inheriting tradition and applying the relevant characteristics of traditional national costume to modern costume design can create new styles for costume and broaden the creative thought of modern costume design to produce more kinds of costume works.

\subsection{Accelerate the National Progress and Development}

National culture plays an important role in the national progress and development, and can be inherited permanently, for example, American Indian culture or Mayan culture. Each of them represents a nation, and even a history of its country. Comparing traditional costume design with modern costume design, we learn the similarity and difference. The similarity is that both of them aim to make better costume works, while the difference is the design pattern adopted. However the development trend that the national culture is perfectly integrated with modern design concept not only inherits good aspects of national cultural tradition, but also creates modern aesthetic concepts. It is killing two birds with one stone. Modern costume design must be based on national costume elements, adopt advanced design concepts and methods, and perfectly integrate traditional national culture with modern design concepts to create perfect and innovative works. The progress and the development of modern countries mainly depend on their economic development and culture progress. Only through increasingly inheriting good aspects of cultural tradition, creating new concepts, and integrating traditional cultural with modern concepts, will it play an indirect part in the economic development of national market.

\section{Apply National Costume Elements to Modern Costume Design}

National costume elements include visual elements and spiritual elements. Visual elements refer to shell fabric, construct, craft, styling, ornament and other elements. Spiritual elements refer to color, pattern and other elements, showing the aesthetic thought and creative consciousness. At present, keeping up with the changes of the times, a majority of designers apply national costume elements to modern fashion costume design and express the spiritual meaning of national culture from a deep aspect. However, many domestic designers begin to pay attention to flexibly utilizing national costume elements which are even integrated with modern costume design to show communications between cultures.

\subsection{The Application of Styling}

When choosing styling elements, designers consider not only people's visual perception brought by the pattern but also the cultural meaning implied in styling elements. Only through a series of considerations about costume design, can both of the sense of modern fashion and national flavor exist at the same time, or there will be a feeling of out of fashion. The most common of women's costume in the Yi nationality is pleated skirt, which is put together by many layers of cloth. Recently, the rainbow pleated skirt, which is relatively fashionable, extends this styling element. The waistband of this rainbow pleated skirt is tight, while the full skirt is rather long. The crumples in each layer distribute equally, and the hemline takes on the shape of horn, and the color is from dark to light. The color contrast of this pleated skirt in the Yi nationality is very sharp, which brings the feeling of brightness and gorgeous. If modern costume design adopts this styling and the harmonious diffuse color at the same time, the costume will bring a feeling of elegance and freshness. Many long modern skirts adopt this design styling, which have special charms.

\subsection{The Application of Pattern}

When designing costume, designers reorganize, refine and graft national costume elements which are perfectly applied to modern costume design. Through this innovative application, the costume produced like this has more artistic effect. Through the perfectly combination of the pattern and the costume, the sense of beauty will be further deepened, and the costume will have more physical and artistic beauty to enrich people's vision and to make the works designed easier to move people. During the period of creation, designers have to grasp the consistency and the necessary connection between costume works and raw materials, rather than blindly copying the original. And without creativity and uniqueness this kind of costume design doesn't conform to the basic requirement of costume design. On the contrary, we can split, partly exaggerate or scatter the design pattern to better set off the design characteristics and to achieve the effect needed. The pattern of national costume is comparatively colorful, for the main part of national costume actually has an irreplaceable effect on conveying feelings and ideas. National costume can't simply imitate the shape of the object but completely shows the characteristics of the object in costume to convey the clearest meaning. As the major object conveying aesthetic emotion and cultural information, the pattern can't be separated from costume but should make them show a complete effect. The pattern of the minority costume tends to come from the real life and all the things in nature. There are hundreds of thousands of patterns in various shapes in nature, such as flowers, birds, insects and fish; the sun, the moon and stars; animals and birds as well as forest trees, which show their own natural beauty and strong life force all the time.

\subsection{The Application of Shell Fabric}

The shell fabric of ethic national costume generally includes two genera. One is the genus of plants, and the other is the genus of animals. The genus of plants principally includes bark, bamboo, grass-blade and so on. The genus of animals mainly includes silk, animal hair and animal furs. In the southern agriculture, every nationality experimentally plant cottons and flaxes and keep silkworms. So much national costume adopts materials of plants, such as the Yao nationality, the Han 
nationality and other nationalities, while most of northern nationalities adopt materials of animals. In the specific progress of costume design, the traditional shell fabric can be combined with costume design, and national characteristics is highlighted by design language can also use these shell fabrics as raw materials and show detailed innovations in works to make the costumes designed more national. So in the current costume design, we can also use these shell fabrics as raw materials and show detailed innovations in works to strengthen aesthetics combined tradition with modern, which will further promote the progress and development of costume design. In national elements, the shell fabric is the most basic element. Traditional national costume mostly adopts animal furs as the shell fabric of costume. For example, sheepskin is one of the most common elements. Women's sheepskin shawl of the Naxi nationality in Lijiang, Yunnan is called traveling day and night. Because two big round ornaments in the upward of sheepskin represent the sun and the moon, and small round ornaments in the downward represent the seven stars and there are bonds made by sheepskin. While in some places, fishskin is adopted, such as the Hezhe nationality, living in the downstream of the Amur River, whose costume mainly made by fishskin is long gown. The style is similar to that of cheongsam, and the length is over knees, and the waistband tight, and the bottom and the hemline rather loose. Its shape is like the folding fan and beneficial to walk. While sleeves are rather loose and short, and there is not a collar. The edge, the back, the collar stay or cuffs, generally, take on the animal and plant pattern, the wave-like shape or the moire shape cut by the colored cloth, dyeing deer or fishskin. Some national minorities adopt woolen costume, especially the woolen capes, which are very rare in southwestern national minorities in our country. The woolen cape is relatively thick with close texture, whose function is keeping warm, preventing moisture and resisting wear.

\subsection{The Application of Ornaments}

In modern costume design, ornaments take a small percentage in costume, while their matching effect is very strong. So matching ornaments which have national customs on costume makes modern design more beautiful. In traditional Tibetan ornaments, there are some mottled and antiquated natural stones, animal bones and corals. Although it sounds that they lack characteristics, the visual effect actually is so good that these ornaments are full of regional customs. These ornaments, earthy and with rich local flavor, make national characteristics and modern fashion coordinate closely. Colorful national ornaments can stimulate designers' inspiration to design more fashionable costume based on national characteristics, and this innovative matching method further embodies the style of costume and carries forward Chinese national style. The application of ornaments also gives the feeling of beauty to people visually and doesn't make the costume too dull and too trivial. This is the key point in modern costume design which must be focused on. The essence of national costume mainly focuses on ornaments from which we can learn implied meanings and profound knowledge of history and culture. Ornaments on national costume include hair accessories, earrings, headgears, anklets and other ornaments. National culture implied in these ornaments and matching interest can let us realize the rich feeling of national culture to provide good theories and innovations for costume design. No matter how luxurious or simple, beautiful and practical, flowery ornaments are, these different ornaments can make us feel national cultural features after carefully tasted, although materials and the matching style are different and they look exceedingly strange on the whole.

\subsection{The Application of Craft}

The technological progress of national costume is the key point to show national costume features. The handmade craft is the processing method of traditional national costume. Some directly process shell fabric or costume, such as embroidery, wax printing, carving or hemstitch and so on. Some add ornaments or accessories to costume to show characteristics in national costume. The craft of modern costume design has been deeply into the domestic and overseas market, which is the inevitable road from traditional technology to modern fashion technology. In the technological process, the tie-dyeing is designed for the whole, but the wax printing is designed for the part. In the design process of modern costume design, the wax printing shows not only feminine charms but also perfect masculine characteristics in men's costume. Some well-known innovative design of men's leisure costume not only flexibly adopts modern technology of wax printing, but also embodies individual characteristics in the form of graffiti. In the process of modern costume design, the technology adopted simplifies the complicated technology of fashion costume to make the process simpler. Therefore, applying technological elements to modern costume design must maintain the original cultural flavor, and possess modern innovative thought at the same time. Perfectly integrating national costume technological elements with modern costume design in design process not only maintains national cultural original flavor, but also conforms to modern aesthetics, which creates a good condition for the development of modern costume design.

\section{Conclusion}

In a word, the concept of modern costume design relatively lags behind to some extent at present, especially when national costume elements are integrated with modern costume design. Although the thought attracts a lot of attention, costume designers still can't apply details of national elements to designing and the works are too stiff and deliberate, which have lost the original intention of costume design. However, we can't abandon traditional national culture. We should inherit the essence of national culture more rationally to make it useful in the progress of increasing progress. With the increasingly rapid development of social economy, costume designers should increase their own technological level to be with high proficiency, carrying 
forward national culture and better applying national elements in national cultural characteristics to modern fashion costume design. National elements will comply with the times, become the fashion trend, and create new thoughts for costume design.

\section{References}

[1] Pu Shu. Research on the Tourism Resource Development and the Protection of Tibetan Costume Culture in Ganzi District[J].Journal of Southwest University for Nationalities (Humanities and Social Sciences Edition). 2010, 31(8): 53-56.

[2] Zang Qing. On the Dural Character of Costume Integration between Man and the Han Nationality in Qing Dynasty[J]. China Science and Technology Review. 2010(32): 530.

[3] Lin Xiaohua. On Artistic and Historical Evolution of National Costume-Costume Art of Ethic Minority from National Costum to Cross-Straits[J]. Daguan Weekly. 2012(51): 39-40.

[4] Qu Xianda. On the Integration of Nation and Era--On the Secondary Design of the National Costume Pattern[J]. Textile Science and Technology. 2012, 41(2): 51-53.

[5] Zhao Yaofeng. On Ningxia National Costume Culture Integration[J]. Journal of Ningxia Normal University. 2010, 31(5): 105-108.

[6] Liu Jinlian, Liu Shuxian. Correctly Interpret the Symbol of National Costume and Rationally Develop the Product of National Costume--Taking the Traditional Costume Development of Xinjiang Uygur as an Example[J]. Art Science and Technology. 2013, 26(4): 85-86.

[7] Huang Yanping. Research on the Geometric Pattern of Chinese Ethnic Minority Costume[J]. Journal of Southwest Normal University (Natural Science Edition). 2010, 35(2): 224-233.

[8] Ping Huang. On the Integration of Chinese Ethnic Minority Costume and Modern Costume Design [J]. China Science and Technology Review. 2011(15): 181. 